\title{
Immunhistochemical Assessment of PD-L1 Expression Using Three Different Monoclonal Antibodies in Triple Negative Breast Cancer Patients
}

Gilda Schmidt ( $\sim$ gilda.schmidt@uks.eu )

Universitätsklinikum des Saarlandes https://orcid.org/0000-0001-9265-2484

Margit Maria Guhl

Saarland University: Universitat des Saarlandes

Erich-Franz Solomayer

Saarland University Hospital and Saarland University Faculty of Medicine: Universitatsklinikum des

Saarlandes und Medizinische Fakultat der Universitat des Saarlandes

\section{Gudrun Wagenpfeil}

UdS: Universitat des Saarlandes

\section{Mohammed Eid Hammadeh}

Saarland University Medical Center and Saarland University Faculty of Medicine: Universitatsklinikum des Saarlandes und Medizinische Fakultat der Universitat des Saarlandes

Ingolf Juhasz-Boess

University of Freiburg Hospital: Universitatsklinikum Freiburg

Jan Endrikat

Saarland University Medical Center and Saarland University Faculty of Medicine: Universitatsklinikum des Saarlandes und Medizinische Fakultat der Universitat des Saarlandes

\section{Mariz Kasoha}

University of Homburg: Universitat des Saarlandes

\section{Rainer Maria Bohle}

Universitätsklinikum des Saarlandes und Medizinische Fakultät der Universität des Saarlandes:

Universitatsklinikum des Saarlandes und Medizinische Fakultat der Universitat des Saarlandes

\section{Research Article}

Keywords: Triple-negative breast cancer, PD-L1 expression, monoclonal antibodies 22C3, 28-8 and SP142

Posted Date: August 24th, 2021

DOI: https://doi.org/10.21203/rs.3.rs-833378/v1 
License: (c) (i) This work is licensed under a Creative Commons Attribution 4.0 International License. Read Full License 


\section{Abstract}

\section{Background:}

PD-L1 receptor expression in breast cancer tissue can be assessed with different anti-human PD-L1 monoclonal antibodies. The performance of three specific monoclonal antibodies in a head-to-head comparison is unknown. Also, a potential correlation of PD-L1 expression and clinico-pathological parameters has not been investigated.

\section{Methods}

This was a retrospective study on tissue samples of patients with histologically confirmed triple negative breast cancer (TNBC). PD-L1 receptors were immune histochemically stained with three anti-human PDL1 monoclonal antibodies: 22C3 and 28-8 for staining of tumor cell membranes (TC) and cytoplasm (Cyt), SP142 for immune cell staining (IC).

Three different tissue samples of each patient were evaluated separately by two observers in a blinded fashion.

The percentage of PD-L1 positive tumor cells in relation to the total number of tumor cells was determined. For antibodies 22C3 and 28-8 PD-L1 staining of 0 to $<1 \%$ of tumor cells was rated "negative", 1 to $50 \%$ was rated "positive" and $>50 \%$ was rated "strong positive". Cyt staining was defined as "negative" when no signal was observed and as "positive", when any positive signal was observed.

For IC staining with SP142 all samples with PD-L1 expression $\geq 1 \%$ were rated as "positive".

Finally, the relationship between PD-L1 expression and clinico-pathological parameters was analyzed.

\section{Results}

Tissue samples from 59 of 60 enrolled patients could be analyzed. Mean age was 55 years.

Both the monoclonal antibodies 22C3 and 28-8 had similar properties, and were positive for both TC in 13 patients (22\%) and for Cyt staining in 24 patients (40.7\%). IC staining with antibody SP142 was positive in 24 patients $(40.7 \%)$, who were also positive for Cyt staining. The differences between TC and Cyt staining and TC and IC staining were significant $(p=0.001)$.

Cases with positive TC staining showed higher Ki67 expression compared to those with negative staining, $40 \%$ vs $30 \%$, respectively $(p=0.05)$.

None of the other clinico-pathological parameters showed any correlation with PDL1 expression.

\section{Conclusion}


Antibodies 22C3 and 28-8 can be used interchangeably for PD-L1 determination in tumor cells of TNBC patients. Results for Cyt staining with 22C3 or 28-8 and IC staining with SP142 were identical. PD-L1 expression correlates with Ki67 expression but not with OS or DFS.

\section{Introduction}

Triple negative breast cancer (TNBC) is a subtype of breast cancer (BC) defined by total lack of hormone receptor expression, i.e., estrogen receptor negative (ER-), progesterone receptor negative (PR-) and human epidermal growth factor receptor negative (Her2neu-). TNBC affects about $15-20 \%$ of women with BC (Metzger-Filho, 2012) (Stovgaard, 2018). Compared to other subtypes, TNBC is the most malignant form of BC (D'Ippolito E, 2013) with early recurrence and early distant metastases (Newman LA, 2015) resulting in a poor prognosis (Metzger-Filho, 2012) (Mittendorf, 2014).

The median overall survival (OS) of metastatic TNBC patients is about 10.2 months (Bonotto, 2014). So far, chemotherapy is the treatment of choice as hormone or antibody therapy lack a suitable target (Jongen L, 2019).

Tumor cells expressing PD-L1 on their cell surface can inactivate immigrating cytotoxic T cells and thus evade destruction (Patel, 2015). New studies on "immune checkpoint inhibitors" block either PD-L1 receptors on the tumor cell or PD-1 receptors on the T cell and consequently allow immune cells to attack (Guha, 2014).

On March 2019, the Food and Drug Administration (FDA) approved the immune checkpoint inhibitor atezolizumab in combination with protein-bound paclitaxel (nab-paclitaxel) for TNBC patients who express PD-L1 > 1\%. In the registration study "Impassion 130" PD-L1 expression was determined with anti-PD-L1 monoclonal antibody SP142 (Schmid, 2019). By inhibiting PD-L1, atezolizumab enables the activation of $T$ cells and thus restores their ability to recognize and destroy tumor cells. (Herbst R.S., 2014).

The aim of this study was to compare the ability of three different anti-human PD-L1 monoclonal antibodies to show PD-L1 expression in tumor and immune cells in women with TNBC. In addition, a correlation between PD-L1 expression and clinico-pathological parameters was explored.

\section{Material And Methods}

\section{Study design}

This retrospective study included women with histologically confirmed TNBC treated at the Department of Gynecology and Obstetrics, Saarland University Medical Center, Homburg/Saar, Germany between the end of 2004 to mid-2013. All patients received surgery but not neoadjuvant chemotherapy. All study data were retrieved from the medical records. The Ethics Committee of Saarland, Germany approved this study. 


\section{Tissue sample preparation}

All formalin-fixed paraffin-embedded (FFPE) tissue blocks were retrieved from the archive of our institute of pathology. The FFPE blocks were cut into $4 \mu \mathrm{g}$ thick tissue slices and stained by hematoxylin-eosin $(H \& E)$ staining. An experienced pathologist with more than 30 years of experience analyzed these sections and defined representative tumor areas for tissue microarray (TMA) construction.

\section{TMA preparation:}

prepared from each TMA block for H\&E- and immunohistochemical (IHC) staining. The pathologist determined the most meaningful areas within each tissue block, sampled three $1 \mathrm{~mm}$ cores from each block using a biopsy needle and placed them into 3 separate micro tubes. These tubes were sent to Zytomed Systems GmbH in Berlin, Germany, for preparation of the TMA blocks, producing a total of 60 cores (from 20 cases with 3 cores each). Finally, four consecutive serial $4 \mu \mathrm{m}$ sections were prepared from each TMA block to be used for H\&E- and immunohistochemical (IHC) staining.

\section{IHC staining}

Three anti-human PD-L1 antibodies were used: antibodies 22C3 and 28 - 8 for staining of membranes and cytoplasm of tumor cells and SP142 for immune cell staining (Table 1).

Table 1

Antibodies used in this study

\begin{tabular}{|lllll|}
\hline $\begin{array}{l}\text { Primary } \\
\text { Antibody }\end{array}$ & Antibody & Vendor & Dilution & Ref. \\
$\begin{array}{l}\text { Anti- } \\
\text { Human } \\
\text { PD-L1 }\end{array}$ & $22 C 3$ & Dako & $1: 50$ & $\begin{array}{l}\text { Dako, Monoclonal Mouse Anti-Human PD-L1 antibody } \\
\text { 22C3. Dako Produktdatenblatt, 2016. }\end{array}$ \\
$\begin{array}{l}\text { Anti- } \\
\text { Human } \\
\text { PD-L1 }\end{array}$ & $28-8$ & Abcam & $1: 200$ & $\begin{array}{l}\text { abcam, Anti-PD-L1 antibody (28 - 8) abcam Product } \\
\text { datasheet, 2015. Q9NZQ7(ab205921): p. 1-11. }\end{array}$ \\
$\begin{array}{l}\text { Anti- } \\
\text { Human } \\
\text { PD-L1 }\end{array}$ & SP142 & Dako & - & $\begin{array}{l}\text { Ventana Medical Systems, I., VENTANA PD-L1 (SP142) } \\
\text { Assay. Ventana Produktdatenblatt, 2018. 1018007DE }\end{array}$ \\
\hline
\end{tabular}

All IHC staining steps were performed at our institute of pathology using an automated staining tool (BenchMark XT, Ventana Medical System, Inc., Tucson, AZ, USA) and two different detection kits: UltraView Universal Alkaline Phosphatase Red kit (antibody 22C3 and 28-8) and OptiView DAB IHC Kit for (antibody142) (Ventana Medical Systems).

After staining, slides were washed under running tap water at approx. $50^{\circ} \mathrm{C}$, hydrated in a series of graded alcohols, rinsed in xylene and finally covered with a mounting medium and a cover glass. 


\section{Documentation}

Slides stained with anti-PD-L1 antibody 22C3 and antibody $28-8$ were scanned using Nikon Supercoolscan ED 5000 scanner to record an overview of the staining. Then, individual cores were analyzed under a Zeiss microscope (Axioskop 40, Carl Zeiss, Germany), and selected images were recorded with a digital camera (AxioCam MRC, Carl Zeiss, Germany) using Axiovision Documentation Rel.4.8 program. Photo documentation of the slides stained with anti-PD-L1 antibody 142 was done using the sacn service from Sysmex (Norderstedt, Germany). Images of scanned sections were later downloaded, viewed, evaluated and documented in various magnifications via the Sysmex Case Viewer (viewer software 3DHistech Case Viewer).

\section{Observers}

Three different samples of each patient were evaluated separately by two observers in a blinded fashion. One was a pathologist from our institution with more than 30 years of experience and the second observer had completed a special training course at the Qualitätssicherungs-Initiative Pathologie $\mathrm{GmbH}$ (QuiP, Berlin, Germany).

\section{Quality \& evaluation criteria}

Valid cases had to show at least 100 evaluable/vital tumor cells, damaged or necrotic cells were excluded.

Staining of anti-PD-L1 antibodies 22C3 and $28-8$ was evaluated in the tumor cell cytoplasma (Cyt) and cell membrane (TC). Membranous staining was recorded as positive if at least one red (i.e. positive) signal could be recorded, irrespective of extent or intensity (Scheel, 2016).

The percentage of PD-L1 positive tumor cells in relation to the total number of tumor cells was scored as follows: PD-L1 expression 0 to < $1 \%$ was rated "negative", 1 to $50 \%$ was rated "positive" and a PD-L1 expression $>50 \%$ was rated "strong positive". Cyt staining was defined as "negative" when no signal was observed and as "positive", when any positive signal was observed (Fig. 1).

In addition, IC staining with antibody SP142 was assessed. Here, individually distributed immune cells, punctiform immune cell and immune cell aggregates in the intra-tumoral stroma were evaluated (Vennapusa B, 2019). Thus, all tumor areas covered by PD-L1 in immune cells were evaluated. Again, the percentage of PD-L1 positive immune cells was calculated as a percentage of the counted tumor cells. Membranous staining of tumor cells was not taken into account. All samples with PD-L1 expression $\geq 1 \%$ were evaluated as PD-L1 "positive" (Schmid, 2018).

In every staining run, tonsil tissue and heart muscle served as positive and negative controls, respectively (Fig. 1).

The results of the individual samples were combined into one result. If the individual percentages from one patient were heterogeneous, the percentage distribution (based on 100 vital tumor cells) in the total 
tumor mass was evaluated.

Finally, the relationship between PD-L1 expression and clinical parameters was analyzed.

\section{Statistical analysis}

Descriptive analysis was applied using absolute and relative frequencies for categorical variables and mean, median and range for continuous variables. McNemar-test was used for testing the association between dependent categorical variables. For group comparisons of quantitative data we used the MannWhitney U-test assuming non-normality. Data were analyzed using SPSS version 25. A two-sided p-value of $5 \%$ or lower was considered statistically significant. We did not correct for the issue of multiple testing due to the explorative nature of the study.

\section{Results}

\section{Study population}

Sixty patients were included in this study, one was excluded because of a lack of tumor cells in the tissue sample. Mean follow-up was 92 months (range 0-153 months).

Mean age was 55 years, 54 patients (90\%) had an invasive ductal carcinoma, 40 patients (66\%) had G3 cancers and 59 (98.3\%) had no metastases (M0) (Table 2). 
Table 2

Clinico-pathological parameters of study population $(\mathrm{N}=60)$

\section{Clinicopathological characteristic}

Age at disease diagnosis (mean/range) years

History of previous tumor

No

Yes*

\section{Histology}

Invasive ductal

Other**

Grading

G1/G2

G3

\section{T Status}

$\mathrm{T} 1$

T2

T3

$\mathrm{T} 4$

N Status

NO

N1/N2/N3

M Status

M0

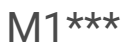

Ki67\%

$\leq 14 \%$

* Ovarian cancer $(\mathrm{N}=1)$, endometrial cancer $(\mathrm{N}=1)$, breast cancer (HER positive) $(n=1)$, and thyroid cancer $(n=1)$

** Invasive lobular $(\mathrm{N}=3)$, tubulo-lobular $(\mathrm{N}=1)$, multicentral $(\mathrm{N}=1)$, and invasive papillary $(\mathrm{N}=1)$.

*** Bone metastases
$55(29-91)$

$N$ (\%)

56 (93.3)

4 (6.7)

54 (90)

6 (10)

20 (33.3)

$40(66.7)$

31 (51.7)

24 (40)

3 (5)

2 (3.3)

44 (73.3)

16 (26.7)

59 (98.3)

1 (1.7)

$6(10)$ 


\section{Clinicopathological characteristic}

$>14 \%$

Unknown

HER2

0

1

2

\section{Disease free survival (DFS):}

Mean follow-up 92 months (range: 0-153 months)

No

Yes

Death:

Mean follow-up 92 months (range: 0-153 months)

No

Yes

* Ovarian cancer $(\mathrm{N}=1)$, endometrial cancer $(\mathrm{N}=1)$, breast cancer (HER positive) $(\mathrm{n}=1)$, and thyroid cancer $(n=1)$

** Invasive lobular $(\mathrm{N}=3)$, tubulo-lobular $(\mathrm{N}=1)$, multicentral $(\mathrm{N}=1)$, and invasive papillary $(\mathrm{N}=1)$.

*** Bone metastases

\section{PD-L1 expression}

Anti-PD-L1 antibody 22C3 and 28 - 8 showed identical results for TC staining (46, 12, and 1 case for negative, positive, and strong positive staining, respectively) as well as for Cyt staining (35 and 24 cases for negative and positive staining, respectively).

IC staining with anti-PD-L1 antibody SP142 was negative in 35/59 cases and positive in 24/59 patients (Table 3). 
Table 3

Protein expression patterns of PD-L1 in tumor and immune cells with 3 monoclonal antibodies $(\mathrm{N}=59)$

\begin{tabular}{|c|c|c|c|c|c|c|c|}
\hline \multirow[t]{2}{*}{$\begin{array}{l}\text { PD-L1 } \\
\text { antibody }\end{array}$} & \multicolumn{3}{|c|}{ Membranous staining (TC) } & \multicolumn{2}{|c|}{$\begin{array}{l}\text { Cytoplasmic staining } \\
\text { (Cyt) }\end{array}$} & \multicolumn{2}{|c|}{$\begin{array}{l}\text { Immuno cells } \\
\text { staining (IC) }\end{array}$} \\
\hline & $\begin{array}{l}\text { Negative } \\
(<1 \%)\end{array}$ & $\begin{array}{l}\text { Positive } \\
(1- \\
50 \%)\end{array}$ & $\begin{array}{l}\text { Strong } \\
\text { positive } \\
(>50 \%)\end{array}$ & Negative & Positive & $\begin{array}{l}\text { Negative } \\
(<1 \%)\end{array}$ & $\begin{array}{l}\text { Positive } \\
(>1 \%)\end{array}$ \\
\hline $22 \mathrm{C} 3$ & $\begin{array}{l}46 \\
(78 \%)\end{array}$ & $\begin{array}{l}12 \\
(20.3)\end{array}$ & $1(1.7 \%)$ & $\begin{array}{l}35 \\
(59.3 \%)\end{array}$ & $\begin{array}{l}24 \\
(40.7 \%)\end{array}$ & -- & - \\
\hline $28-8$ & $\begin{array}{l}46 \\
(78 \%)\end{array}$ & $\begin{array}{l}12 \\
(20.3)\end{array}$ & $1(1.7 \%)$ & $\begin{array}{l}35 \\
(59.3 \%)\end{array}$ & $\begin{array}{l}24 \\
(40.7 \%)\end{array}$ & - & - \\
\hline SP142 & - & - & - & - & - & $\begin{array}{l}35 \\
(59.3 \%)\end{array}$ & $\begin{array}{l}24 \\
(40.7 \%)\end{array}$ \\
\hline \multicolumn{8}{|c|}{ TC: Tumor cell } \\
\hline \multicolumn{8}{|c|}{ Cyt: Cytoplasma } \\
\hline IC: Immun & & & & & & & \\
\hline
\end{tabular}

\section{PDL1 staining patterns}

Positive staining with antibodies 22C3 and 28 - 8 was significantly higher in Cyt compared to TC, 24/59 patients $(40.7 \%)$ vs $13 / 59(22 \%)(p=0.001)$. ICs stained with antibody SP142 showed the same positive staining patterns as Cyt, i.e. $24 / 59$ patients $(40.7 \%)(p \geq 0.05)$. Thus, the difference between TC staining and IC staining was also significant $(p=0.001)$.

All cases with positive TC staining showed also positive staining in Cyt and IC. The cases with positive staining in Cyt and IC were identical. A correlation between Cyt staining with antibodies 22C3 and $28-8$ vs IC staining with antibody SP142 has been proven (Fig. 2).

\section{PD-L1 expression vs clinico-pathological characteristics}

Cases with positive TC staining showed significantly higher Ki67 expression compared to those with negative staining, $40 \%$ vs $30 \%$, respectively $(p=0.05)$ (Fig. 3$)$.

None of the other clinico-pathological parameters shown in Table 2, including OS/PFS, showed any correlation with PDL1 expression.

\section{Discussion}

This study compared the ability of three different anti-human PD-L1 monoclonal antibodies to show PDL1 expression in tumor and immune cells of women with TNBC. Monoclonal antibodies 22C3 and $28-8$ can be used interchangeably for assessing PD-L1 expression on tumor cells. Results for Cyt staining with 
22C or $28-8$ and IC staining with SP142 were identical. No correlation between PD-L1 expression and clinico-pathological parameters was found.

PD-L1 expression assessed with antibodies 22C3 and $28-8$ showed similar results for TC and Cyt staining. However, this result is only valid for breast cancer tissue, in particular valid for patients with TNBC. This may not apply to other tumor entities. However, results on non-small-cell lung cancer were similar (Scheel, 2016) (Hirsch, 2017).

While this study could not prove any correlation of PD-L1 expression with survival, Huang et al. showed in a meta-analysis on 14,367 BC patients that PD-L1 expression on tumor cells associates with high-risk clinico-pathological parameters and poor prognosis. However, PD-L1 in combination with tumor infiltrating lymphocytes may relate to significantly longer DFS $(p=0.001)$ and OS $(p<0.0001)$. Comprehensive assessment of TCs and TILs is required when evaluating the clinical relevance of PD-L1 expression in future studies (Huang, 2019).

While no correlation between IC staining and clinico-pathological parameters could be demonstrated, Schmid et al. showed in a large phase III study, that metastatic TNBC patients with PD-L1 expression of $\geq 1 \%$ in ICs benefit from therapy with the checkpoint inhibitor atezolizumab in combination with nabpaclitaxel. Schmid et al. reported an improvement in progression-free survival of 5 versus 7.5 months (HR $0.62, p<0.0001)$ and in OS of 15.5 vs. 25 months (Schmid, 2019).

Similarily, Brockhoff et al. reported longer DFS and OS in 103 TNBC patients with PD-L1 expression. They state that PD-L1 expression indicates an enhanced immunological anti-tumor activity resulting in favorable prognosis (Brockhoff, 2018).

Finally, Reis et al. showed in urothelial carcinoma that PD-L1 expression in ICs has a higher predictive value than PD-L1 expression in TCs (Reis, 2019).

\section{Correlation of PD-L1 expression and clinico-pathological parameters}

Although PD-L1 expression is considered a clinically relevant prognostic parameter (Gluz, 2020) (Schmid, 2018), no correlation between PD-L1 expression and clinico-pathological parameters was found in this study. In contrast, Gluz et al. recently published a sub-analysis of the ADAPT study showing TNBC patients with high PD-L1 expression had a higher pCR rate (pathological complete remission, $p<0.05$ ) and also a significant longer OS (Gluz, 2020). Notably, one patient in this study with PD-L1 expression of $>50 \%$ was reported to be disease-free for over 10 years.

However, there was one exception: patients with positive TC staining showed significantly higher Ki67 expression compared to those with negative staining, $40 \%$ vs $30 \%$, respectively $(p=0.05)$ (Fig. 3$)$. Both Ki67 and TC staining indicate a higher malignancy of the tumor. These results confirm the studies by Doğukan R et al and Huang W et al. (Doğukan R., 2019) (Huang, 2019). 


\section{Limitations}

The following limitations need to be addressed: 1.) The cohort of 59 valid cases was small, Ki67 could be determined in 49 patients only; 2 .) It is unknown whether the cores taken for the tissue sample were representative for the whole tumor, in particular in highly heterogenous cancers.

\section{Conclusion}

Antibodies 22C3 and $28-8$ can be used interchangeably for PD-L1 determination in TBNC patients. Results for Cyt staining with 22C or $28-2$ and IC staining with SP142 were identical. PD-L1 expression correlates with Ki67 expression but not with OS or DFS.

\section{Declarations}

\section{Authors contribution:}

Gilda Schmidt: project development, data sampling, manuscript writing

Margit Maria Guhl: support project development, manuscript reviewing

Erich-Franz Solomayer: manuscript reviewing

Gudrun Wagenpfeil: statistical analysis

Mohammed Eid Hammadeh: manuscript reviewing

Ingolf Juhasz-Böss: manuscript reviewing

Jan Endrikat: manuscript editing und reviewing, support writing

Mariz Kasoha: support writing, manuscript editing und reviewing

Rainer Maria Bohle: support project development, manuscript reviewing

\section{Conflict of interest and financial disclosure:}

None of the authors declared any conflict of interest

\section{References}

1. Adams S, et al (2014) Prognostic value of tumor-infiltrating lymphocytes in triple-negative breast cancers from two phase III randomized adjuvant breast cancer trials: ECOG 2197 and ECOG 1199. J Clin Oncol. 2014, S. 32(27): p. 2959-66 
2. Bonotto $\mathrm{M}$ et al (2014) Measures of outcome in metastatic breast cancer: insights from a real-world scenario. Oncologist. 2014, S. 19(6): p. $608-15$

3. Borghaei $\mathrm{H}$, et al (2015) Nivolumab versus Docetaxel in Advanced Nonsquamous Non- Small-Cell Lung Cancer. N Engl J Med. 2015, S. 373(17): p. 1627-39

4. Brockhoff G, et al (2018) The presence of PD-1 positive tumor infiltrating lymphocytes in triple negative breast cancers is associated with a favorable outcome of disease. Oncotarget. 2018, S. 9(5): p. 6201-6212

5. Burstein MD, et al (2015) Comprehensive genomic analysis identifies novel subtypes and targets of triple-negative breast cancer. Clin Cancer Res 2015(7):1688-1698 S. 21 )

6. Cottrell TR, Taube JM (2018) PD-L1 and Emerging Biomarkers in Immune Checkpoint Blockade Therapy. Cancer J. 2018, S. 24(1): p. 41-46

7. de Melo Gagliato, D., et al. 2017. Tumor-infiltrating lymphocytes in Breast Cancer and implications for clinical practice. Biochim Biophys Acta Rev Cancer. 2017, S. 1868(2): p. 527-537

8. Denkert C, et al (2018) Tumour-infiltrating lymphocytes and prognosis in different subtypes of breast cancer: a pooled analysis of 3771 patients treated with neoadjuvant therapy. Lancet Oncol. 2018, S. $19(1)$ : p. $40-50$

9. D'Ippolito E, lorio MV (2013) MicroRNAs and triple negative breast cancer. Int J Mol Sci. 2013, 14(11):22202-20

10. Doğukan R, et al (2019) Correlation between the Expression of PD-L1 and Clinicopathological Parameters in Triple Negative Breast Cancer Patients. Eur J Breast Health. 2019, 15(4):235-241. doi: 10.5152/ejbh.2019.4912. PMID: 31620682; PMCID: PMC6776123.

11. Esteva FJ, et al (2019) Immunotherapy and targeted therapy combinations in metastatic breast cancer. Lancet Oncol. 2019, S. 20(3): p. e175-e186

12. Fremd C, Jaeger D, and Schneeweiss A (2018) Targeted and immuno-biology driven treatment strategies for triple-negative breast cancer: current knowledge and future perspectives. Expert Rev Anticancer Ther. 2018, S. p. 1-14

13. Garon EB, et al (2015) Pembrolizumab for the treatment of non-small-cell lung cancer. N Engl J Med. 2015, S. 372(21): p. 2018-28

14. Gluz O, et al (2020) Efficacy of de-escalated chemotherapy according to PAM50 subtypes, immune and proliferation genes in triple-negative early breast cancer: Primary translational analysis of the WSG-ADAPT-TN trial. Int J Cancer. 2020, S. 146(1):262-271

15. Guha M (2014) Immune checkpoint inhibitors bring new hope to cancer patients. The pharmaceutical Journal. 2014, S. 293(7837/8)

16. Herbst RS, et al (2014) Predictive correlates of response to the anti-PD-L1 antibody MPDL3280A in cancer patients. Nature. 2014, 515(7528): p. 563-7

17. Herbst RS, et al (2016) Pembrolizumab versus docetaxel for previously treated, PD-L1- positive, advanced non-small-cell lung cancer (KEYNOTE-010): a randomised controlled trial. Lancet. 2016, 
S. 387(10027): p. 1540-50

18. Hirsch FR, et al (2017) PD-L1 Immunohistochemistry Assays for Lung Cancer: Results from Phase 1 of the Blueprint PD-L1 IHC Assay Comparison Project. J Thorac Oncol. 2017, S. 12(2): p. 208-222

19. Huang W, et al (2019) Prognostic and clinicopathological value of PD-L1 expression in primary breast cancer: a meta-analysis. Breast Cancer Res Treat. 2019, 178(1):17-33. doi: 10.1007/s10549019-05371-0. Epub 2019 Jul 29.PMID: 31359214

20. Jezequel $P$, et al (2015) Gene-expression molecular subtyping of triple-negative breast cancer tumours: importance of immune response. Breast Cancer Res. 2015, S. 17: p. 43

21. Jiao S, et al (2017) PARP Inhibitor Upregulates PD-L1 Expression and Enhances Cancer- Associated Immunosuppression. Clin Cancer Res 2017(14):3711-3720 S. 23 )

22. Jongen $L$, et al (2019) Tumor characteristics and outcome by androgen receptor expression in triplenegative breast cancer patients treated with neo-adjuvant chemotherapy. 2019

23. Keir ME, et al (2008) PD-1 and its ligands in tolerance and immunity. Annu Rev Immunol. 2008, S. 26: p. 677-704

24. Lehmann BD, et al (2016) Refinement of Triple-Negative Breast Cancer Molecular Subtypes: Implications for Neoadjuvant Chemotherapy Selection. PLoS One. 2016, S. 11(6): p. e0157368

25. Loi S, et al (2013) Prognostic and predictive value of tumor-infiltrating lymphocytes in a phase III randomized adjuvant breast cancer trial in node-positive breast cancer comparing the addition of docetaxel to doxorubicin with doxorubicin-based chemotherapy: BIG 02-98. J Clin Oncol. 2013, S. 31(7): p. $860-7$

26. Metzger-Filho 0 , et al (2012) Dissecting the heterogeneity of triple-negative breast cancer. $J$ Clin Oncol. 2012, S. 30(15): p. 1879-87

27. Mittendorf EA, et al (2014) PD-L1 expression in triple-negative breast cancer. Cancer Immunol Res. 2014, S. 2(4): p. $361-70$

28. Monneur A, Goncalves A, and Bertucci F (2018) [PD-L1 expression and PD-1/PD-L1 inhibitors in breast cancer]. Bull Cancer. 2018, S. 105(3): p. 263-274

29. Newman LA, et al (2015) The 2014 Society of Surgical Oncology Susan G. Komen for the Cure Symposium: triple-negative breast cancer. Ann Surg Oncol. 2015, 22(3):874 - 82

30. Normanno N, et al (2013) Molecular diagnostics and personalized medicine in oncology: challenges and opportunities. J Cell Biochem. 2013, S. 114(3): p. $514-24$

31. Patel SP, Kurzrock R (2015) PD-L1 Expression as a Predictive Biomarker in Cancer Immunotherapy. Mol Cancer Ther 2015(4):847-856 S. 14 )

32. Reis H, et al (2019) PD-L1 Expression in Urothelial Carcinoma With Predominant or Pure Variant Histology: Concordance Among 3 Commonly Used and Commercially Available Antibodies. Am J Surg Pathol. 2019, S. 43(7): p. 920-927

33. Scheel AH, et al (2016) [Predictive PD-L1 immunohistochemistry for non-small cell lung cancer: Current state of the art and experiences of the first German harmonization study]. Pathologe. 2016, 
S. 37(6): p. $557-567$

34. Schmid P, et al (2018) Atezolizumab and Nab-Paclitaxel in Advanced Triple-Negative Breast Cancer. N Engl J Med. 2018, S. 379(22): p. 2108-2121

35. Schmid P, Chui SY, and Emens LA (2019) Atezolizumab and Nab-Paclitaxel in Advanced TripleNegative Breast Cancer. Reply. N Engl J Med. 2019, S. 380(10): p. 987-988

36. Stovgaard ES, et al (2018) Triple negative breast cancer - prognostic role of immunerelated. Acta Oncol. 2018, S. 57(1): p. 74-82

37. Tumorzentrum München BI,. 2015. Mammakarzinome. s.l.: Zuckschwerdt Verlag GmbH fürMedizin und Naturwissenschaften,5. Auflage edition, 2015

38. Vennapusa B et al (2019) Development of a PD-L1 Complementary Diagnostic Immunohistochemistry Assay (SP142) for Atezolizumab. Appl Immunohistochem Mol Morphol. 2019, Feb;27(2):92-100. doi: 10.1097/PAl.0000000000000594. PMID: 29346180; PMCID: PMC6369970

Figures

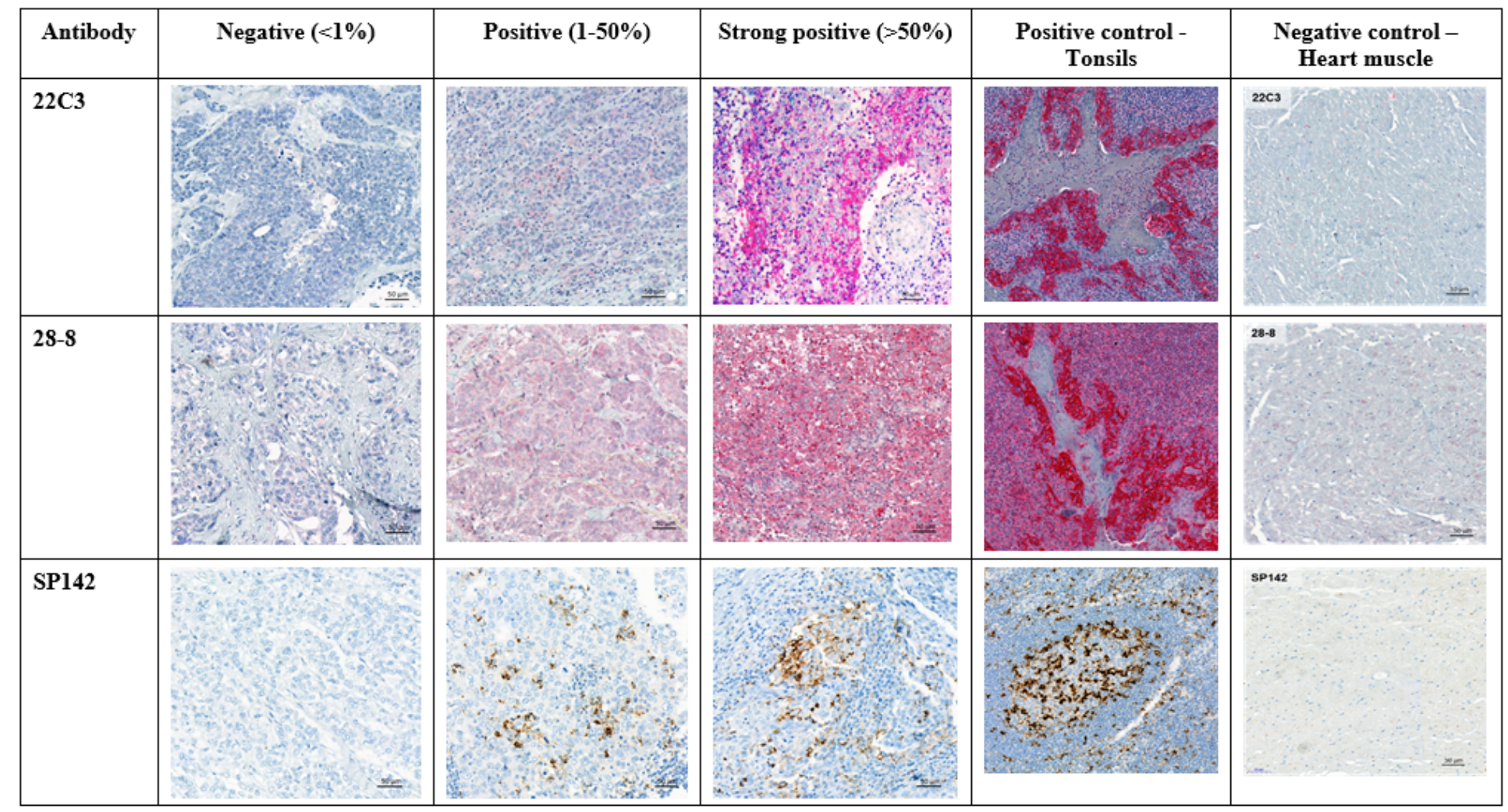

\section{Figure 1}

Immunhistochemical staining of tumor tissue and controls with three anti-PD-L1 monoclonal antibodies 


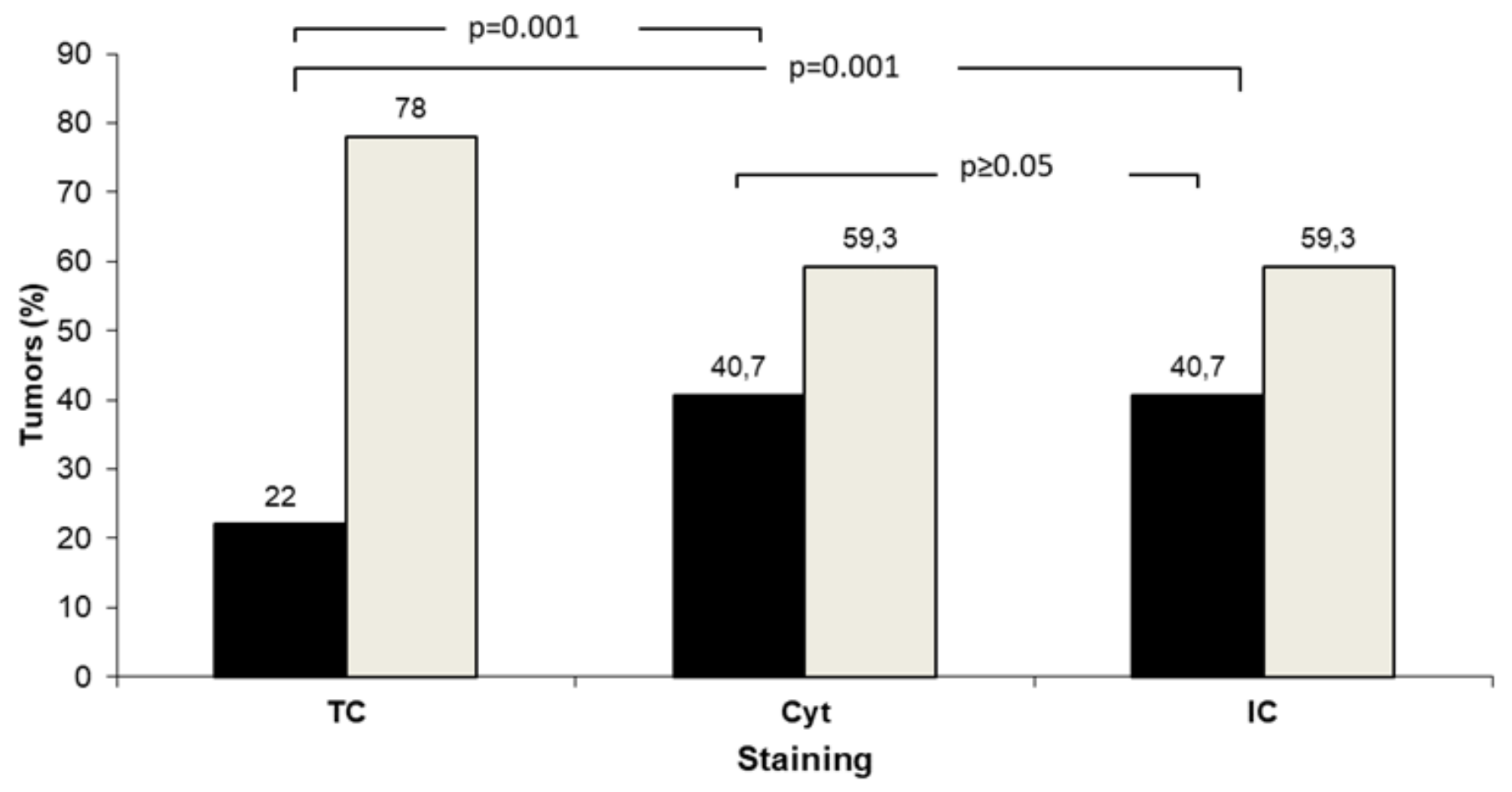

- Positive $\square$ Negative

Figure 2

Staining patterns of tumor cell membranes (TC), tumor cell cytoplasm (Cyt) and immune cells (IC) with either antibody 22C3 and 28-8 combined or SP142 N=59 TC and Cyt staining assessed with antibodies 22C3 and 28-8 IC staining assessed with antibody SP142 


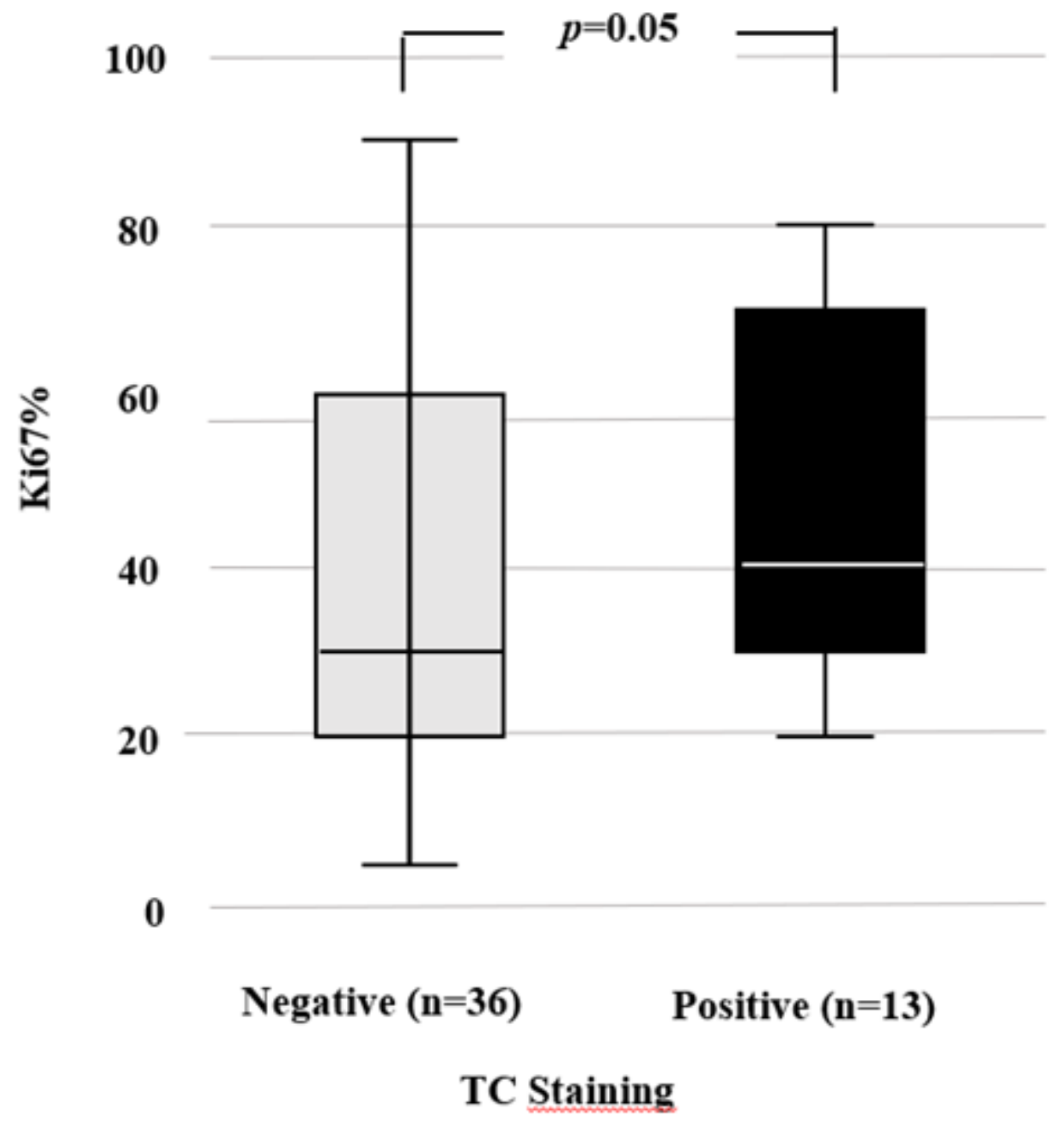

Figure 3

Mean Ki67 expression by TC staining patterns of PD-L1 using antibodies 22C3 and 28-8 